\title{
GNOSIS: Knowledge Systematization; Configuration Systems for Design and Manufacturing
}

\author{
Moriki Toyama \\ International Coordinator of GNOSIS, Mitsubishi Electric \\ Corporation \\ 5-1-1 Ofuna, Kamakura, Kanagawa, Japan \\ Phone: +81-467-41-2845, Fax: +81-467-41-2143, \\ E-mail: toyama@ims.isl.melco.co.jp
}

\begin{abstract}
GNOSIS is one of the founding research consortia in the international Intelligent Manufacturing Systems research program. GNOSIS aims to establish the framework for a new manufacturing paradigm through the utilization of knowledge-intensive strategies covering all stages of product life cycle, in order to realize new forms of highly competitive manufactured products and manufacturing processes which are environment-conscious, society-conscious and human-oriented. The project objectives, current situation and its background are described in this paper.
\end{abstract}

\section{Keywords}

Manufacturing, IMS, GNOSIS, New paradigm, Knowledge systematization, Soft artifacts, Virtual manufacturing, Enabling technology, Knowledge highway, Knowledge capitalization, Modeling, Life cycle, Knowledge intensive engineering

\section{INTRODUCTION}

The role of manufacturing has recently been brought into question due to the undesirable effects it causes -- environmental problems such as natural resource depletion and excess waste generation, and international trade friction as evidenced by the emergence of trade 
blocks and the necessity for complex trade agreements. Reactive and uncoordinated remedies are being applied to these problems, achieving only short-term, partial success. Without a coordinated, radical initiative, the manufacturing sector will be faced with either self-imposed or externally-imposed restrictions in the coming years. The work proposed here is an initial but significant step in this initiative.

Based on its experience in the international IMS Feasibility Study, the GNOSIS Consortium has established a research program consisting of 5 work packages focusing on research themes considered essential for the achievement of the above aims. Knowledge systematization forms the basis on which the work will be carried out, supporting enabling technologies and research into the development of soft artifacts (socially desirable, reconfigurable and reusable systems, components and products) and virtual manufacturing through distributed, networked enterprises. These new products and production systems will be designed using knowledge intensive engineering in order to realize the long term aims of the work, namely, the post mass production paradigm.

\section{BACKGROUND AND STATE OF THE ART}

Although advances brought about by the present information society have improved many aspects of human life, they have not addressed the fundamental problems associated with mass production -- excessive use of natural resources and pollution. Companies are now facing new challenges on top of conventional concerns such as quality and cost. They have to respond quickly not only to changing market demands, but also to environmental pressures and international trade issues. To solve the these problems, the influence of manufactured products on their natural environment and on the global economy has to be investigated. This requires an expansion of the conventional limits of the manufacturing domain to include the entire product life cycle. These issues have not been addressed by conventional information technologies, which tend to focus on data and information and do not have a systematized approach to the treatment of knowledge. In the manufacturing domain this has resulted in localized but not global consistency, and advances in specific areas of product development, but not comprehensive thinking about life cycle issues.

In order to change the current production paradigm, we have to reformulate manufacturing concepts, through comprehensive use of knowledge. Knowledge, of itself, will not solve the problems. Rather, effectively systematized knowledge applied to achieve new, innovative technologies is needed to realize the shift in paradigm. With the aim of design for complete product life cycle, methodologies for realizing new soft, reconfigurable artifacts based on reusable components are being studied in GNOSIS. New production facilities and concepts, which are necessary to achieve these soft artifacts, are also being investigated, as the core of research into the virtual factory.

GNOSIS is taking a unique approach toward overcoming current problems in the manufacturing world which have been and are being tackled by several other projects both within and without the IMS Program. Firstly, GNOSIS is distinguished by its emphasis on the need for a paradigm shift, while other programs up to now have tended towards extending the current paradigm and merely trying to improve it. Secondly, other manufacturing research has generally focused on specific issues or domains, and has not tackled the underlying issues. As noted in the reports of the Test Case, GNOSIS has and will continue to tackle the 
problems in a holistic way, not separating design from manufacturing, and manufacturing from environment.

\section{PROJECT OBJECTIVES, RESULTS AND OVERVIEW}

\subsection{Objectives and Industrial Relevance}

The GNOSIS Project is a result-oriented, proactive initiative aiming at a future manufacturing paradigm compatible with both the natural environment and human-society. Thus the objectives are oriented towards the environment, the consumer and the manufacturer:

The industrialized economies are fast approaching a period when mass production and mass consumption will be unable to maintain economic growth and increasing wealth. Therefore, there is a need for a manufacturing paradigm shift that will permit a transition from mass production to post one's patterns of economic activity. Among the salient points, the following are representative:

- Modern engineering can only produce the most circumscribed solutions to the destruction of the global environment, and manufacturing engineering displays an ignorance of global issues.

- Intellectual work is becoming an important component of the industrialized world. The nature of production work is changing and more emphasis is placed on cognitive tasks as opposed to manual work.

- Knowledge is quickly becoming the one most important resource in production systems. Manufacturing companies are selling not only physical products, but also knowledge and information.

- Greater flexibility is required due to higher renewal rates of products, shorter product life-cycles, reduced delivery time, increased customization of products, and JIT philosophies.

- Companies which are structured according to conventional principles are no longer able to respond adequately to change.

The ultimate goal of GNOSIS is to establish a framework for a new manufacturing paradigm which will overcome or minimize the problems inherent in the existing mass production paradigm. Thus a post mass production paradigm (PMPP) is proposed. This involves a new approach to manufacturing, recognizing resource limitations and the balance of nature in order to achieve a sustainable manufacturing environment. The new paradigm will be realized by the manufacture of soft products, with their associated production systems and industrial enterprises. Softness here refers to adaptability, robustness, and growth potential together with congeniality to the natural environment and human society. The lack of such softness in conventional manufactured products is due largely to the uncoordinated use of knowledge, resulting in conceptual blind-spots-local optimization but global inconsistencies. Hence, the effective use of knowledge is regarded as the key to the establishment of the new paradigm.

It is knowledge systematization which will make possible these soft products, soft artifacts and soft manufacturing. Knowledge systematization includes the classification, structuring and organization of knowledge within a systematic framework, giving consideration to the dynamic aspects of knowledge, and the creation of shared ontologies. In this way, the relevant 
enabling technologies will be built up availing of knowledge systematization techniques, and knowledge deployment will permit the soft artifacts and virtual manufacturing to be implemented.

The principal objectives of GNOSIS can be outlined as follows:

(1) Environmental Objectives: Modern lifestyles with their reliance on mass manufacturing and mass consumption have caused environmental problems which are gradually forcing a reappraisal of the products and processes supporting the industrialized world. Society is being compelled to move towards the adoption of products which are easily maintained, upgradable, and designed for recycling. The realization of soft products will reduce the volume of manufacturing from today's levels, thus reducing material usage and pollutant by-products and making manufacturing more environmentally friendly. In manufacturing systems the use of upgradable soft machines will also directly reduce the material consumption and production associated with supplying conventional production machinery which is scrapped when outdated. To be upgradable, such soft machines need to be modular and designed to be re-configurable and upgradable.

(2) Consumer-Oriented Objectives: The human user or consumer of manufactured products is a powerful influence in manufacturing. The consumer drives the rapid introduction of new models, a wider range of equipment options and styling, and the market-place demands for value and price. It is also the underlying reason why "agile manufacturing" has become necessary. What we see is the first stage of a trend towards making products more human-friendly in all respects. The second stage, which is just beginning, will increasingly focus on making them customizable and user-adaptable. To satisfy this demand for human-friendly customization and the movement in manufacturing towards the "batch size of one", manufacturing systems will have to be dynamically re-configurable to suit rapidly changing production needs. The realization of such systems will involve the implementation of virtual factory concepts and intelligent network implementations. These systems will permit geographically distributed production facilities small in size compared to today's often massively concentrated production.

(3) Manufacturer-Oriented Objectives: The role of the manufacturer is also central to any research into future products and production. The manufacturer aims at satisfying customer requirements for the lowest possible price and desired quality of goods. The objective of staying at the competitive edge in the manufacturing domain requires that new technologies and research ideas be implemented at the earliest possible stage. Adaptable, upgradable products, machines and manufacturing systems can respond effectively to this pressure.

Thus it can be seen that soft manufacturing involves more than being environmentally friendly. It also implies manufacturing which is sufficiently adaptable to respond to human needs for variety, customization, performance and price. It means human-society-responsive manufacturing in another sense as well. If the production facilities become geographically distributed networks with many of the units being smaller than at present, this could be seen as being both "human friendly" as well as "environmentally friendly", bringing to reality the adage "small is beautiful". 


\subsection{Expected Major Results and Advances in the State-of-the-Art}

The principal themes of the research were selected to enable the objectives outlined above and the strategies proposed to be implemented at various levels, so as to achieve results in the short to medium, as well as the long-term. Research into the PMPP goal will include conceptual themes such as social needs, manufacturing philosophy, and the economy, in addition to considering the driving forces and obstacles to it. Research into new competitive soft artifacts and virtual manufacturing, which will form the backbone of the future manufacturing paradigm, will be supported by knowledge systematization and a knowledge intensive engineering framework, with enabling technologies and integration themes focusing on specific issues.

Expected results include the development of enabling tools and technologies for the design and manufacture of new soft artifacts, and also for the achievement of virtual manufacturing. Various examples of soft artifacts will be produced and tested, in the short to medium term. This work will provide a test bed for the full scale production of soft products. The virtual manufacturing research will also be tested and demonstrated in experimental factories before being extended to actual production. Work on the PMPP will provide a blue-print for the transition to the new paradigm, while the knowledge systematization research will form the basis of a "manufacturing knowledge highway" on top of the existing information highway.

In summary, this research proposes a shift from mass material use in production to mass knowledge application, from quantitative to qualitative satisfaction, and the widening of the scope of manufacturing to include the whole product life cycle. The consortium approach towards realizing that goal is by small concrete steps accomplished in technical tasks focused on concrete goals and deadlines.

\subsection{Scope and International Dimensions}

The scope of the GNOSIS Project covers all aspects of manufacturing: the product, production and the enterprise; the human user or consumer; and the natural environment. In order to avoid any tendency towards a dilution of effort due to this wide scope, the project is concentrated on the attainment of new competitive, environmentally friendly products and production, using knowledge technologies as a foundation.

The rationale for carrying out the proposed research at an international level, involving partners from all the major industrial economies of the world is as follows:

(1) The environmental aspects of manufacturing and consumption cannot be tackled at a local or regional scale, since the environmental consequences of manufacturing and mass consumption are global in scale and necessitate a global approach toward resolving them. Without a world-wide consorted strategy, a rational sustainable balance between manufacturing and the environment cannot be achieved.

(2) The effective use of knowledge as a foundation for tackling world-wide problems requires access to all available knowledge sources. Manufacturing knowledge, environmental knowledge and global market knowledge are not concentrated in any particular region or country but are distributed throughout the world. Thus a research program which utilizes such knowledge must have access to it wherever it is located, and therefore must involve all concerned countries.

(3) Manufacturing is no longer a national or regional concern. The gradual opening of national markets and the international pressure to open up closed markets, the strengthening of world trade bodies, and the consumer desire for the free flow of 
products and services, require that a global scope be adopted for any development of new products and production technologies.

(4) The recent advances in communication technologies, as evidenced by advanced electronic networks, multi-media transfer of information and knowledge, and the internationalization of research, make global-level collaborative research feasible for the first time. Such an opportunity should be utilized to advance the living standards and knowledge level of human society.

The GNOSIS Project has partners with experience of environmental issues and market conditions from all the main industrial regions of the globe. Furthermore, they have access to the important knowledge sources for achieving concrete results in the research. Extensive use of state-of-the-art communication technologies is facilitating progress in the project, and the extra value added by collaborating at an international level is ensuring globally balanced, pragmatic, technological advances.

\subsection{Project Overview and Approach}

The long-term goal of the GNOSIS project is to develop a new manufacturing paradigm which recognizes problems of the present manufacturing environment -- the growing scarcity of natural resources, the problem of environmental destruction, and the issues arising out of regional trade imbalances. The new PMPP is based on systematization of design and manufacturing knowledge to acquire and organize knowledge in a form that supports the design and manufacturing of soft artifacts, i.e., products and factories which achieve reduced resource utilization and waste elimination throughout the whole life cycle from design to recycling or disposal. Major technologies to be investigated include configuration management systems supporting the reuse of engineering and manufacturing knowledge in routine design, and configurable production systems achieving dynamic product-specific manufacturing in flexible production systems. The major characteristics, critical drivers, and obstacles to the PMPP will be studied to guide the work towards the new paradigm.

Electronic communication media will be exploited in order to minimize travel overheads, while ensuring mutual understanding and effective coordination on the research themes. Electronic networks set up during the Test Case will be further expanded. The sharing of methodologies and tools between partners will be continued and inter-regional experiments further developed. Knowledge systematization throughout a complete product life cycle will form an important part of the work.

The consortium approach towards realizing that goal is to have a project structure consisting of 5 linked work packages, each composed of several tasks. Each task will have a sharp technical and industrial focus and limited scope. Some of the tasks will develop tools, introducing softness methodologies and knowledge-oriented strategies, and providing enabling technologies. Others will address the concepts and models that are needed in order to implement the envisioned shift in production paradigm. The number and content of the tasks will evolve over the project duration, as old goals are reached or proven irrelevant and as new goals emerge.

\subsection{Technical Themes}

The themes of GNOSIS can be summarized as the development and integration of key enabling technology for the improvement of products and production. This will be achieved through the deployment and capitalization of systematized knowledge in order to move 
towards a future PMPP. The project is structured in 5 interrelated work packages, corresponding to the technical themes. The relationships between the themes are shown in Figure 1:
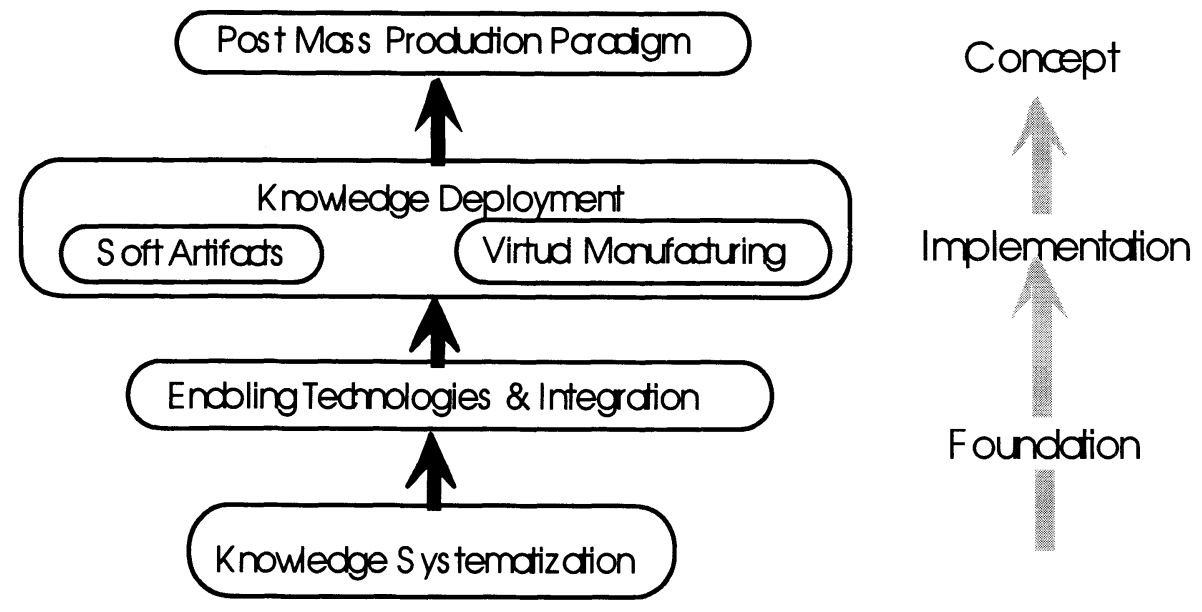

Figure 1 Principal Themes of GNOSIS.

\section{PROJECT WORKPLAN}

\subsection{International Cooperation}

The international dimensions have been outlined in section 3.3, emphasizing the rationale behind the global scope of the GNOSIS project. The environmental aspects, the use of knowledge as a fundamental resource, the globalization of markets and the possibilities provided by advances in electronic communication support the ideas behind the GNOSIS effort. Cooperation between the major industrial regions, Japan, Europe and North America exceeded expectations during the Test Case, both as regards input of human and other resources, and as regards the results obtained. The GNOSIS project will continue to build on this international cooperation, with work package participation by all the major regions, as shown in the next section.

\subsection{Work Packages, Description and Resource Provisions}

The GNOSIS project is organized into a set of 5 conceptually connected, but otherwise autonomous, broad work packages that provide top-down overall control to ensure convergence of the research goals. These work packages consist of more concise, shorter term and technically focused tasks that provide the technical basis, the enabling technology and the deployment actions for the project. The total effort distribution across all regions and work packages is shown in the table 1, after which each of the 5 work packages and their constituent tasks are outlined. Schedules for the tasks to be done in each work package are given for the initial 4 year period, after which further planning can be carried out, as required. 
Table 1 Total Effort Distribution (in Person-Years) over Initial 4 Years

\begin{tabular}{|c|c|c|c|c|c|}
\hline \multirow[b]{2}{*}{ Work package } & \multicolumn{4}{|c|}{ Regions } & \multirow{2}{*}{$\begin{array}{l}\text { Total } \\
\text { Effort } \\
\text { (in WPs) }\end{array}$} \\
\hline & Japan & $\begin{array}{l}\text { European } \\
\text { Union }\end{array}$ & $\begin{array}{c}\text { North } \\
\text { Americ } \\
a \\
\end{array}$ & $\begin{array}{c}\text { Other } \\
\text { Regions* }\end{array}$ & \\
\hline $\begin{array}{l}\text { WP1: } \\
\text { Post Mass Production Paradigm }\end{array}$ & --- & --- & --- & --- & 30 \\
\hline $\begin{array}{l}\text { WP2: } \\
\text { Enabling Technologies \& } \\
\text { Integration }\end{array}$ & --- & --- & --- & --- & 57 \\
\hline $\begin{array}{l}\text { WP3: } \\
\text { Knowledge Systematisation }\end{array}$ & --- & --- & --- & --- & 62 \\
\hline $\begin{array}{l}\text { WP4: Knowledge Deployment 1: } \\
\text { Design of Soft Artifacts }\end{array}$ & --- & --- & --- & --- & 79 \\
\hline $\begin{array}{l}\text { WP5: Knowledge Deployment 2: } \\
\text { Virtual Manufacturing }\end{array}$ & --- & --- & --- & --- & 62 \\
\hline $\begin{array}{c}\text { Total Effort } \\
\text { (in each Region) }\end{array}$ & 120 & 124 & 19 & 27 & 290 \\
\hline
\end{tabular}

*Other Regions: EFTA (Switzerland)

\section{Work Package WP1: Post Mass Production Paradigm}

\section{- Scope and Objectives}

The objective of this work package is to construct the framework for a new manufacturing paradigm that addresses the need to maintain competitiveness in a future consumer society with stringent environmental, market and customer constraints. PMPP research will be used as the global, long-term stimulus for all other activities within GNOSIS. It will provide recommendations for fields of action and supporting tools and methodologies in order to realize artifacts consistent with the PMPP. The knowledge deployment work packages covering soft artifact and virtual factory research will form a key role in the realization of the new paradigm. Topics to be covered will include the definition and evaluation of PMPP-concepts, the identification of key influences at different levels (society, enterprise and shop floor), development of models and tools to run hybrid companies, and development of guidelines to enable fully comprehensive, complete life cycle design of artifacts.

The proposed PMPP will influence society and enterprises, and vice versa, requiring the consideration and investigation of this bi-directional relationship. The rigidity and resistance to change within organizations, both governmental and corporate, are further important factors to be tackled. In the proposed PMPP, companies will have to redesign themselves in order to achieve the required modularity and flexibility.

\section{- Tasks and Deliverables}

Task 1: Concepts of PMPP

Task 2: Interactions of the PMPP with Enterprise, Environment and Society

Task 3: Softness in the PMPP Context 
Deliverables: 1) An in-depth study of guiding principles for future total manufacturing from design to disposal, 2) Recommendations for fields of action for company strategies.

\section{Work Package WP2: Enabling Technologies and Integration}

\section{- Scope and Objectives}

The objective of this work package is to develop the tools and concepts that support other work packages of GNOSIS, namely, the new production paradigm, knowledge deployment and knowledge systematization, and to facilitate their integration in order to reach the overall goals of GNOSIS. Three main complementary areas will be investigated: i) softness methodologies, ii) modeling, and iii) integration.

These areas are explained as follows: 1) Softness methodologies will define and develop the different concepts, principles and technologies required to implement new and powerful functionalities, such as autonomy, adaptability, flexibility and growth potential in any artifact, system or organization. Such softness characteristics are prerequisites for the realization of soft artifacts and soft machines, 2) The objective of modeling is to develop theories, methodologies and prototype implementations to support knowledge deployment in the soft product life cycle, virtual production systems and modeling of soft enterprises, all of which relate to the required characteristics of the future manufacturing paradigm, and 3) The integration research will contribute to the building of distributed intelligent tools to support product life cycle design, the assessment of soft products and enterprises as well as knowledge systematization techniques. The systems to be developed will complement human agent activities in the enterprise, and will ensure the full consistency of all the tasks undertaken in GNOSIS.

\section{- Tasks and Deliverables}

Task 1: Softness Methodologies

Deliverables: 1) concepts and tools for developing soft artifacts and soft machinery, 2) methods for achieving re-configurable and autonomous production systems, 3) methods and models for non-linear dynamic and chaotic systems to achieve stability and adaptability

Task 2: Modeling; Tools/methods for life cycle product modeling will be developed, in addition to methodologies for simulating environmental impact. Enterprise modeling will also be studied.

Deliverables: 1) Product life cycle modeling methods and tools for future manufacturing paradigms, 2) Modeling of enterprise information and decision systems, adapted to permit flexibility, 3) A proposal for hybrid semi-autonomous organizational structures, 4) Demo. and evaluation of the new methods/tools on selected industrial processes/products.

Task 3: Integration; This task covers specification/implementation of tools for distributed intelligent environments, and develop interface using such tools to coordinate research activities.

Deliverables: 1) Development of distributed intelligent systems for production systems, 2) Tools for total life cycle modeling, virtual factory, soft products, and other knowledge systematization activities, 3) Demo. of distributed intelligent systems, focusing on organizational/social impacts. 


\section{Work Package WP3: Knowledge Systematization}

\section{- Scope and Objectives}

The aims of this work package are: 1) to apply engineering knowledge more efficiently to engineering tasks, in order to enable the realization of the PMPP. This is called knowledge intensive engineering, 2) to capture, reuse, and update knowledge concerning the complete product life cycle covering design, production, marketing, operation, maintenance, recycling, etc. This is regarded as a prerequisite for the efficient deployment and exploitation of knowledge and for its evolution. The whole process is referred to as "knowledge systematization."

The objective of this work package is to build a framework on which a new style of engineering activities, called "knowledge intensive engineering," can take place. Knowledge intensive engineering puts emphasis on more intelligent ways of using engineering knowledge in order to realize soft artifacts and knowledge based manufacturing enterprises. The framework developed in this work package will consist of methodologies, tools and techniques for knowledge intensive engineering, as well as guidelines for their practical implementation. The whole process of developing the framework will be supported and guided by research and experimentation involving organizational, environmental and economical aspects, as well as existing and new technologies. The work package gives a knowledge intensive infrastructure for the knowledge deployment work packages, WP4 and WP5, by using technologies supplied from the integration/enabling technology work package, WP2.

Domains covered will include: design rationale, deep design knowledge, manufacturing knowledge, and other knowledge for product life cycles. Technological, organizational, and methodological aspects will be considered.

Topics will cover: knowledge modeling, knowledge capturing, dynamic knowledge systematization, integrated knowledge management, knowledge encapsulation, integration of knowledge based deployment tools, reasoning techniques, knowledge sharing and reuse, inter-model communications (STEP and other models), knowledge exploitation, knowledge analysis and abstraction, knowledge maintenance, knowledge discovery, dynamic navigation of knowledge use, knowledge media. In the evaluation tasks, different groups of partners will focus on one aspect of one topic in one domain.

\section{- Tasks and Deliverables}

Task 1: Establishment of Knowledge Intensive Engineering Framework; This task will involve a survey of current knowledge application practices and identification of needs for the establishment of a knowledge intensive engineering framework (KIEF).

Deliverable: Requirements analysis report for KIEF.

Task 2: Techniques and Organizations for Capturing Knowledge; This task will cover existing and future strategies for acquiring, representing and systematizing knowledge, in order to facilitate its reuse and transferability.

Deliverables: 1) Guidelines for improved knowledge management, 2) Guidelines for where, when, and how to capture/systematize knowledge, 3) Development of software prototypes of knowledge tools employed.

Task 3: KIEF Development and Integration; Development of KIEF, together with its integration with other GNOSIS work. Experimentation will be carried out using the 
knowledge deployment work packages to determine requirements for further development. The results of the enabling technologies work package will be utilized.

Deliverables: 1) Reports on KIEF architecture, methodology and functional specification of required technological development, 2) Development of prototypes of KIEF.

Task 4: Application of KIEF; The KIEF framework developed will be applied to various problems in the other GNOSIS work packages, particularly those dealing with knowledge deployment, in order to carry out detailed evaluations.

Deliverables: 1) Reports concerning experimental evaluations, 2) Reports on current practices, organizational and corporate strategies for knowledge use. Guidelines for implementation of KIEF in various business sectors.

\section{Work Package WP4: Knowledge Deployment 1: Design of Soft Artifacts}

\section{- Scope and Objectives}

The scope of this work package covers theories, methods and tools for applying systematized knowledge in order to realize soft artifacts and move towards the post pass production paradigm. Results from the enabling technologies and knowledge systematization work packages will be used to develop and implement tools. Requirements concerning knowledge deployment in design will be fed back to these work packages and will also provide input to the virtual manufacturing work package.

To achieve minimum use of natural resources and the minimum impact on the environment, soft artifacts must be closely matched to requirements as they will have many more variants with increased one-off or low-volume production than conventional products. In addition, the design and configuration of the artifact will have to take into account all life cycle stages, e.g., usage, maintenance, re-configuration, reuse and disposal.

\section{- Tasks and Deliverables}

Task 1: Design methodologies

Deliverables: Generic design methodologies in order to attain softness in artifacts, including modularity, self-organization, autonomy, reconfigurability and selfmaintainability.

Task 2: Configuration Methods

Deliverables: Design configuration tools

Task 3: Examples of Soft Artifacts:

Deliverables: 1) Examples of soft artifacts including both software and hardware, 2) Evaluation of tools and methodologies

\section{Work Package WP5: Knowledge Deployment 2: Virtual Manufacturing}

\section{- Scope and Objectives}

The objective of this work package is to promote the transition from the current manufacturing paradigm to the PMPP by developing and applying virtual factory and manufacturing concepts.

The virtual factory refers to the use of modeling and simulation to enable the integration of all aspects of management of manufacturing. Systematized product and 
manufacturing knowledge is used as a fundamental resource for the creation of the manufacturing process and also for its management. This knowledge is combined with soft artifact concepts and the enabling technologies provided by other work packages in order to realize the virtual factory, which in turn will provide feedback to other work packages.

The study and development of reconfigurable tools for management of decentralization and customization in manufacturing will form a key theme in the research. Other specific matters to be addressed include the implementation of distributed architectures and supporting systems, in addition to self-organization concepts and on-line re-configuration and control. The ultimate goal is to provide companies with improved methodologies/tools for more competitive management.

\section{- Tasks and Deliverables}

Task 1: Knowledge Based Process Design; Tools and methods for automated process planning based on systematized knowledge for both product/production systems will be developed.

Deliverables: 1) Software capable of automatically creating process plans containing information needed by NC-code generators (feature based factory model and manufacturing knowledge), 2) Advanced graphical user interface easing the control of information for process plan creation

Task 2: Development of simulation technology; In this task simulation technology is applied to areas such as manufacturing, construction, ergonomics, training and prototyping. Distributed modeling and simulation will also be evaluated from the concurrent engineering perspective.

Deliverables: 1) Definition of linkages between factory simulators and real production databases, 2) Definition of data needed for advanced process simulators.

Task 3: Exploration of emerging scheduling paradigms; An efficient management of time is critical for the success of a company. Increasing flexibility in the manufacturing processes is continuously raising the degree of freedom in scheduling. This fact will also have implications on the structure of the organizations.

Deliverables: 1) Analysis of scheduling requirements in distributed and non-distributed manufacturing environments, 2) Specification and evaluation of scheduling architectures, 3) Implementation of prototypes in both simulated and real factory environment.

Task 4: Development of architecture for Virtual Factory environment

Different technologies supporting the virtual factory concept will be integrated in order to address the organization of distributed manufacturing.

Deliverables: 1) Specification for interfaces between different virtual factory functionalities and environments, 2) Implementation of results of work-packages in real production processes.

Task 5: Pilot test cases for the Virtual Factory concept

The virtual factory concept will be applied and evaluated in pilot cases covering different areas in the manufacturing process: construction, shop floor, assembly.

Deliverables: 1) Prototype installations , 2) Benchmarking report 


\section{CONSORTIUM COMPOSITION}

\section{Regions Involved:}

Japan, EU, Canada, EFTA, (US participation under negotiation)

International Coordinating Partners:

Japan Region:

Mitsubishi Electric Corporation

European Union (EU) Region: ADEPA (Agence de la Productique)

Canada Region:

EFTA Region:

KSI University of Calgary

ETH Zurich

\section{Regional Consortium Partners:}

\section{Japan Region}

Coordination Partner: Mitsubishi Electric Corporation

Industrial Partners: Mitsubishi Electric, Shimizu, Kajima, Chiyoda , Yamatake Honeywell Academic Partners: University of Tokyo, Nara Advanced Institute of Science and

Technology, Osaka University, ASTEM

\section{European Union (EU) Region}

Coordination Partner: ADEPA (Agence de la Productique)

Industrial Partners: ADEPA, IBM France, BICC , ITMI-Aptor , ABB, Tehdasmallit Oy, Becos, Siemens, Schenck Eng., SKET.

Academic Partners: Cambridge University, LLP-Cesalp, Helsinki University of Technology, Tampere University of Technology, Ecole des Mines, IAF Magdeburg National Research Institutes: Fraunhofer Institute IPA, Technical Research Center of Finland VTT.

\section{EFTA Region}

Coordination Partner: Swiss Federal Institute of Technology ETH Zurich

Academic Partners: Swiss Federal Institute of Technology EPFL, Swiss Federal Institute of Technology ETHZ.

\section{Canada Region}

Coordination Partner: KSI University of Calgary

Academic Partners: DME University of Calgary, KSI University of Calgary

\section{CONCLUSIONS AND ACKNOWLEDGEMENTS}

This paper has described the objectives and present situation of the GNOSIS consortium with the international IMS research program. The development of this collaborative research is a joint development with many GNOSIS consortium colleagues, especially, Prof. T.Tomiyama (University of Tokyo, Japan), Prof. B.R.Gaines (University of Calgary, Canada), Prof. B.Faltings (EPFL, Switzerland) and Prof. M.Måntylå (HUT, Finland). Please contact the author if you have some interest in GNOSIS. Newcomers interested in the objectives described are welcome to join the GNOSIS consortium. 